\title{
Post-Obstructive Diuresis: Physiopathology, Diagnosis and Management after Urological Treatment of Obstructive Renal Failure
}

\author{
Sumba Harrison 1,2*, Abdelouahed Lasri ${ }^{1,2}$, Youness Jabbour ${ }^{1,2}$, Amine Slaoui ${ }^{1,2}$, Jacquet Djamal ${ }^{3}$, \\ Tariq Karmouni, ${ }^{1,2}$, Kadir El Khader ${ }^{1,2}$, Abdelatif Koutani, ${ }^{1,2}$, Ahmed Ibn Attiya Andaloussi, ${ }^{1,2}$ \\ ${ }^{1}$ Department of Urology “B”, Ibn Sina University Hospital, Rabat, Morocco \\ ${ }^{2}$ Faculty of Medicine and Pharmacy, Mohamed V University, Rabat, Morocco \\ ${ }^{3}$ Department of Uro-Andrology, Faculty of Health Sciences, Cotonou, Benin \\ Email: ^harrysumba98@gmail.com
}

How to cite this paper: Harrison, S., Lasri, A., Jabbour, Y., Slaoui, A., Djamal, J., Karmouni, T., El Khader, K., Koutani, A. and Andaloussi, A.I.A. (2018) Post-Obstructive Diuresis: Physiopathology, Diagnosis and Management after Urological Treatment of Obstructive Renal Failure. Open Journal of Urology, 8, 267-274.

https://doi.org/10.4236/oju.2018.89030

Received: July 30, 2018

Accepted: September 2, 2018

Published: September 5, 2018

Copyright ( $) 2018$ by authors and Scientific Research Publishing Inc. This work is licensed under the Creative Commons Attribution International License (CC BY 4.0).

http://creativecommons.org/licenses/by/4.0/

\section{(c) (i) Open Access}

\begin{abstract}
Obstructive acute renal failure is both a medical and a surgical emergency. The first treatment modality is urological by relief of obstruction. Post-obstructive diuresis is an abnormal condition of prolonged polyuria, involving both excessive solute and water loss, after acute drainage of obstructed urinary tract system. Physiopathology mechanisms are multiples. In most patients, diuresis will resolve once the kidneys normalize the volume and solute status and homeostasis is achieved. Post-obstructive diuresis can occur in up to $50 \%$ of patients with substantial urinary tract obstruction and can be life-threatening if it becomes pathologic. It can be detected by hourly monitoring of diuresis. Medical treatment of post-obstructive diuresis consists of oral or intravenous fluids adjusted to the findings of clinical examination, diuresis (volume and electrolytes) and close monitoring of patient. Fluid compensation should be tapered off over several days. Patients at high risk of post-obstructive diuresis should be identified and appropriately monitored.
\end{abstract}

\section{Keywords}

Post-Obstructive Diuresis, Acute Renal Failure, Water and Electrolyte Compensation

\section{Introduction}

Post-obstructive diuresis (POD) is defined as the condition of prolonged urine production of at least $200 \mathrm{ml}$ for at least two consecutive hours immediately following the relief of urinary retention or similar obstructive uropathy. It may also be 
defined as more than $3000 \mathrm{ml}$ over 24 hours [1] [2]. It's potentially life-threatening polyuria that can develop after the release of the obstruction in various ways, such as insertion of Foley catheter for obstructed bladder, percutaneous nephrostomy (PCN), double-J stent in patients who have bilateral ureteric obstruction or unilateral ureteric obstruction in a solitary functioning kidney [3] [4] [5].

POD is not typically an issue unless the residual urine is $1500 \mathrm{cc}$ or more. If the POD condition becomes pathologic, it can cause serious consequences such as dehydration, electrolyte abnormalities, hypovolemic shock, and even result to death.

\section{Sources of Information}

Data was collected from articles in MedLine and PubMed and we attempt to provide through review of literature a basic, simplified guide toward understanding issues related to the pathophysiology, diagnosis, and treatment of POD. English was employed and the key words were "post-obstructive dieresis", "acute renal failure", "pathogenesis" and "management of post-obstructive dieresis". Research and analysis of articles was conducted between October 2017 and may 2018.

From the articles, data relating to pathophysiology, epidemiology, risk factors, diagnosis, and management were considered for inclusion.

\section{Physiopathology}

Diuresis is a normal physiologic response to help eliminate excess volume and solutes accumulated during the prolonged obstruction. In most patients, diuresis will resolve once the kidneys normalize the volume and solute status and homeostasis is achieved. Some patients will continue to eliminate solute and water even after homeostasis has been reached, referred to as pathologic POD. These patients are at risk of severe dehydration, electrolyte imbalances, hypovolemic shock, and even death if fluid and electrolyte replacement is not initiated.

Post-obstructive diuresis physiopathology is complex to understand because this affection is based on different physiological, biochemical, hormonal and immunological mechanisms evolving in time.

Three main factors are implicated [6] [7] (Table 1).

Tubulopathy:

It is characterized by an impairment of dilution and concentration capacity and a decrease in sodium reabsorption [7] [8]. Leakage of potassium, magnesium and phosphorus is possible in cases of prolonged obstacle [9].

Alteration of urine acidification capacity is also possible [7] [10]. Decrease in secretion of $\mathrm{H}+$ ions has been observed in animals in ureteral obstruction of over 24 hours [11].

Experimentally, an obstructed kidney becomes less receptive to the action of ADH (antidiuretic hormone) [7] [12], although production of this hormone is stimulated by the increase in osmotic load (hypernatremia) [13]. 
Table 1. Post-obstructive physiopathological mechanisms.

\begin{tabular}{|c|c|c|}
\hline Tubulopathy & $\begin{array}{l}\text { Physiopathological state caused } \\
\text { by acute renal failure }\end{array}$ & $\begin{array}{l}\text { Biochemical and } \\
\text { immunological factors }\end{array}$ \\
\hline $\begin{array}{l}\text { Damage to the } \\
\text { dilution-concentration capacity }\end{array}$ & Sodium overload & Atrial natriuretic factor \\
\hline $\begin{array}{l}\text { Decreased sodium } \\
\text { reabsorption }\end{array}$ & $\begin{array}{c}\text { Hyperuricemia, } \\
\text { hypercreatininaemia }\end{array}$ & $\begin{array}{l}\text { Prostaglandins, prostacyclins, } \\
\text { thromboxane A2, endothelins, }\end{array}$ \\
\hline $\begin{array}{l}\text { Leakage of potassium, } \\
\text { magnesium and phosphorus }\end{array}$ & $\begin{array}{l}\text { Hyperkalemia, metabolic } \\
\text { acidosis }\end{array}$ & Macrophage Infiltrate \\
\hline $\begin{array}{c}\text { Decrease in } \mathrm{H}+\text { ions secretion in } \\
\text { urine }\end{array}$ & Dilutional hyponatraemia & Increase in PAF and cytokines \\
\hline Insensitivity to $\mathrm{ADH}$ & & \\
\hline
\end{tabular}

ADH: Antidiuretic hormone; PAF: platelet activation factor.

Physiopathological state caused by acute renal failure:

This is a state of fluid overload that depends on fluid intake and completeness or not of the obstacle. There are also increased levels of nitrogen catabolites: hyperuremia, hypercreatininaemia, as well as hyperkalemia and metabolic acidosis. Hyponatremia is linked to fluid intake (dilution).

Biochemical and immunological mechanisms:

The action of atrial natriuretic factor has been demonstrated in humans, especially in cases of complete obstacle [10].

Prostaglandins [7] [8], prostacyclins, thromboxane A2, endothelins have been described as playing a role in this pathophysiology.

Immunological mechanisms are also in play [7], as long as there is a macrophage infiltrate of an obstructed kidney and elevation of PAF (platelet activation factor) and cytokines [13].

The risk of dehydration is significantly increased in case of incomplete obstacle with renal insufficiency of conserved diuresis because fluid overload is low or even zero.

The polyuric phase lasts approximately 48 hours after release of the obstacle. During this period, intense and brutal polyuria can lead to dehydration, even to shock. Thus, initially obstructive acute renal insufficiency can become functional.

POD is more frequent and important as much as the obstacle is complete and prolonged. Ureteral obstruction, whether uni or bilateral, leads to increased renal vascular resistance and intra-ureteral pressure.

However, diuresis is more important after bilateral than unilateral decompression of obstacle. This is explained by volemic expansion, urea and electrolyte levels which contribute to increase in diuresis and natriuresis [14].

\section{Diagnosis}

Post-obstructive diuresis is a clinical diagnosis based on urine output after decompressing an obstructed bladder or ureter. 
It is difficult to predict which patients will develop POD after the release of urinary tract obstruction. A recent article by Hamdi et al. identified the initial presence of a high serum creatinine level, high sodium bicarbonate level, and urinary retention as independent risk factors for developing POD after decompression [15].

However, some studies have found that the presence of renal insufficiency, heart failure, dizziness, and central nervous system depression are risk factors for developing substantial POD [1] [16].

Apart from age and sex, other risk factors associated with an increased risk of urinary retention include lower urinary tract symptoms, prostate disease, long-standing diabetes, recurrent catheterization, fecal impaction, and the use of anticholinergic medications.

Diagnosis criteria though not limited to the above factors includes identifying patients who have such risk factors and close monitoring of the patient's overall fluid status, urine output and serum electrolyte levels. Hourly monitoring of urine specimens obtained for volume, osmolality, sodium and urea. Clinical observation of weight every 8 hours, repeat blood studies at least every 24 hours and occurrence of postural hypotension or tachycardia. Patients with azotemia are also considered to be at high risk for POD and should be managed accordingly.

There are very few clues to help identify which patients with physiological post-obstructive diuresis will progress to the more dangerous pathological variety. There does not appear to be a strict correlation with serum creatinine, electrolyte levels, creatinine clearance or the presence of hypertension and the eventual development of post-obstructive diuresis. However, there is some association with renal failure or insufficiency, congestive heart failure, and volume overload. Patients presenting signs of dehydration, altered mental status, arrhythmias and decompressed heart failure need strict monitoring. A thorough patient's medical history, a good performed physical examination, and appropriate interpretation of laboratory data are mandatory to identify patients with or at risk for POD.

The incidence of POD is unclear but estimates suggest $0.5 \%$ to $52 \%$ of patients will experience POD after relief of obstruction [17]. It is important to have a high index of suspicion for this condition so that it can be recognized promptly and managed.

Early diagnosis is necessary because the osmotic polyuria that appears is sometimes important with a volume greater than one liter per hour. It is essential to compensate for urinary losses.

Initial clinical examination makes it possible to assess the patient's state of hydration by simple parameters such as weight and in particular the variation of this one with respect to the usual weight. Dehydration is confirmed if there is thirst, skinfold, tachycardia, orthostatic hypotension in a context of weight loss. Conversely, hydro-solute inflation state results in weight gain, edema of the 
lower limbs, high blood pressure. If none of these signs exist, the weight is stable and the blood pressure is normal, the patient is normovolemic.

A urine sample should be collected for analysis of urinary sodium and potassium levels and urine osmolality to determine if it is a solute or urea-type of diuresis. Urea diuresis is generally self-limiting, whereas solute diuresis can convert to pathologic POD and requires careful monitoring of serum electrolyte levels and hydration status. Spot urine sodium levels greater than $40 \mathrm{mEq} / \mathrm{L}$ suggests renal tubular injury and if prolonged can lead to pathologic POD [16].

\section{Treatment}

Treatment of POD should be directed toward complete relief of urinary tract obstruction, replacement of electrolytes, correction of intravascular volume, and appropriate patient monitoring.

The polyuric phase lasts about 48 hours, during which strict monitoring is necessary [18]. The purpose of surveillance is to timely detect POD which manifests by intense polyuria. Hourly diuresis must be monitored.

Polyuria may have hemodynamic consequences in the absence of compensation. Hemodynamic state must be monitored: a regular measure of blood pressure and heart rate is essential [6] [7].

Post-obstructive diuresis treatment principles.

According to Glabeke, there are two different situations [6].

1) Patient with altered consciousness:

- Important saline parenteral perfusion is prescribed, for example 3 liters per 24 hours.

- Diuresis will only be compensated if there signs of dehydration and hypovolemia.

- In situations requiring compensation, polyuria can be maintained by the compensation itself.

Decrease in blood urea and urinary density below 1007 are two indicators that allow the decrease then interruption of compensation.

2) Conscious patient and able to drink:

- Important saline parenteral perfusion of about 3 liters per 24 hours and oral fluid intake.

- Patients adjust their fluid balance and natremia on their own, by drinking to their thirst.

- Intravenous supply is interrupted when urea has sufficiently decreased.

According to Herody, there are three different situations [18].

1) Normovolemic patient:

- Regularly quantify, for example every three hours, volume and urinary electrolytes and compensates at $100 \%$ during the first 24 hours.

- Urine output compensation will be reduced to $75 \%$ on the second day then to $50 \%$ on the third day, and so forth until compensation interruption in a few days. 
2) Patient with sodium overloaded:

- The principle of compensation can be applied in minimal proportions $(75,50$ or even $30 \%$ on the first day) because the initial output is already positive.

- Polyuria that follows POD allows to decrease sodium overload.

3) Patient in dehydration:

- Increase compensation ( $125 \%$ or $150 \%$ on first day) because the initial output is negative.

- Polyuria, if not compensated to more than $100 \%$, will aggravate dehydration. Management of POD has two major risks.

- Hydroelectrolytic compensation insufficiency with risk of extra or intracellular dehydration.

- Excess of hydroelectrolytic compensation with risk of maintaining polyuria. Hydroelectrolytic compensation insufficiency could be the consequence of:

- Insufficient or irregular supervision with underestimation of output.

- The presence of another cause of dehydration: vomiting, hemorrhage.

- Inadequate intake with overvaluation of oral intake.

Excess hydroelectrolytic compensation could be due to:

- Lack of supervision with overvaluation of output.

- Underestimation of oral intake.

\section{Prognosis}

The recovery of renal function after relief of obstruction depends on the duration and degree of obstruction, whether the obstruction is unilateral or bilateral and or whether there is a concomitant infection. Relief of urinary tract obstruction may result in massive diuresis, which needs a meticulous management with appropriate fluids and electrolytes.

In replacing the fluid output in polyuria, care should be taken that the replacement volume does not exceed two-thirds of the daily urinary output, to avoid iatrogenic extracellular volume expansion.

Pathological POD puts the patient at risk for hypovolemia and hemodynamic instability as well as acid-base disturbances and electrolyte imbalances.

Complications that may arise: volume depletion, hyponatremia/hypernatremia, hypokalemia, hypomagnesemia, metabolic acidosis, hypovolemic shock and death.

\section{Conclusions}

Most patients who undergo relief of complete urinary tract obstruction will retain or quickly recover normal renal function and accordingly avoid POD. Patients at high risk for POD should be identified and appropriately monitored.

Diuresis should be monitored. Serial urine and serum parameters should be used to guide appropriate intravenous fluid replacement with the endpoint of maintaining intravascular volume and restoring baseline renal function. Early diagnosis and treatment of pathologic POD will prevent mortality. 


\section{Financial or Other Competing Interests}

The authors declare no financial or competing interest regarding the publication of this paper.

\section{Authors Contribution}

All mentioned authors have contributed to the elaboration and development of this manuscript.

\section{References}

[1] Vaughan Jr., E.D. and Gillenwater, J.Y. (1973) Diagnosis, Characterization and Management of Postobstructive Diuresis. Journal of Urology, 109, 286-292. https://doi.org/10.1016/S0022-5347(17)60406-3

[2] Bishop, M.C. (1985) Diuresis and Renal Functional Recovery in Chronic Retention. British Journal of Urology, 57, 15. https://doi.org/10.1111/j.1464-410X.1985.tb08973.x

[3] Sophasan, S. and Sorrasuchart, S. (1984) Factors Inducing Post-Obstructive Diuresis in Rats. Nephron, 38, 125-133. https://doi.org/10.1159/000183293

[4] Harris, R.H. and Yarger, W.E. (1975) The Pathogenesis of Post-Obstructive Diuresis. The Role of Circulating Natriuretic and Diuretic Factors, Including Urea. Journal of Clinical Investigation, 56, 880-887. https://doi.org/10.1172/JCI108167

[5] Schlossberg, S.M. and Vaughan Jr., E.D. (1984) The Mechanism of Unilateral Post-Obstructive Diuresis. Journal of Urology, 131, 534-536. https://doi.org/10.1016/S0022-5347(17)50485-1

[6] Van Glabeke, E., Corsia, G. and Belenfant, X. (2004) Prise en charge médicale des syndromes de levee d'obstacle. Progres En Urologie, 14, 423-426.

[7] Clabault, K. (2005) Le syndrome de levée d'obstacle. Réanimation, 14, 534-538. https://doi.org/10.1016/j.reaurg.2005.09.004

[8] Jones, D.A., Atherton, J.C., O’Reilly, P.H., et al. (1989) Assessment of the Nephron Segments Involved in Post-Obstructive Diuresis in Man, Using Lithium Clearance. British Journal of Urology, 64, 559-563. https://doi.org/10.1111/j.1464-410X.1989.tb05307.x

[9] Edwards, G.A., Crumb, C.K. and Suki, W.N. (1987) Renal Handling of Phosphate Following Release of Ureteral Obstruction. Mineral and Electrolyte Metabolism, 13, 377-384.

[10] Capelouto, C.C. and Saltzman, B. (1993) The Pathophysiology of Ureteral Obstruction. Journal of Endourology, 7, 93-103. https://doi.org/10.1089/end.1993.7.93

[11] Valles, P., Merlo, V., Beron, W., et al. (1999) Recovery of Distal Nephron Enzyme Activity after Release of Unilateral Ureteral Obstruction. Journal of Urology, 161, 641-648. https://doi.org/10.1016/S0022-5347(01)61987-6

[12] Frokiaer, J., Marples, D., Knepper, M.A., et al. (2012) Bilateral Ureteral Obstruction Downregulates Expression of Vasopressin-Sensitive AQP-2 Water Channel in Rat Kidney. American Journal of Physiology, 270, F657-668.

[13] Reyes, A.A., Robertson, G. and Klahr, S. (1991) Role of Vasopressin in Rats with Bilateral Ureteral Obstruction. Proceedings of the Society for Experimental Biology and Medicine, 197, 49-55. https://doi.org/10.3181/00379727-197-43223

[14] Wein, A.J., Kavoussi, L.R., Novick, A.C., Partin, A.W. and Peters, C.A. (2007) 
Campbell-Walsh UROLOGY: Pathophysiology of Urinary Tract Obstruction. 9th Edition, Elsevier, Saunders, 1195-1226.

[15] Hamdi, A., Hajage, D., Van Glabeke, E., Belenfant, X., Vincent, F., Gonzalez, F., et al. (2012) Severe Post Renal Acute Kidney Injury, Post-Obstructive Diuresis and Renal Recovery. BJU International, 110, E1027-1034.

https://doi.org/10.1111/j.1464-410X.2012.11193.x

[16] Gonzalez, C.M. (2004) Pathophysiology, Diagnosis, and Treatment of the Postobstructive Diuresis. In: McVary, K.T., Ed., Management of Benign Prostatic Hypertrophy, Humana Press, New York, 35-45.

[17] Nyman, M.A., Schwenk, N.M. and Silverstein, M.D. (1997) Management of Urinary Retention: Rapid versus Gradual Decompression and Risk of Complications. Mayo Clinic Proceedings, 72, 951-956. https://doi.org/10.1016/S0025-6196(11)63368-5

[18] Herody, M. (2008) Prise en charge d'un syndrome de levée d'obstacle (SLO) après traitement urologique d'une anurie obstructive. Progres En Urologie, 18, F25-28. https://doi.org/10.1016/S1761-676X(08)70015-4 